\title{
Artificial intelligence in thoracic diseases: the next technology to improve individual precision medicine
}

Precision medicine, also called "individualized medicine", mainly focuses on preventing and treating diseases tailored to the patient according to the patient's genes, environment, and lifestyle. Its purpose is to treat the right patient at the right time in the proper way. Past precision medicine research tended to divide all patients into different subgroups based on evidencebased medicine, and different treatments were given to each subgroup. However, precision medicine should be tailored to each patient's unique treatment plan, which is difficult because it is impossible to write such medical guidelines or expert consensus. The development of artificial intelligence technology is expected to provide a personalized treatment plan for each patient's condition to provide genuinely individualized treatment.

There is an old saying in China that the superior doctor prevents illness, while the inferior doctor treats actual illness. This is true in the field of respiratory medicine today. For lung cancer and other malignant diseases, early diagnosis and treatment are essential measures to improve the survival of patients, and their effects are far better than any innovative treatment developed for advanced diseases. For chronic obstructive pulmonary disease, early diagnosis and timely intervention can also significantly improve the prognosis of patients. Early diagnosis has become very important in modern medicine, especially for respiratory diseases. Early diagnosis based on imaging with the assistance of artificial intelligence can significantly improve the stability and accuracy of diagnosis while saving labor costs. In the final stage of lung disease, drug screening based on deep learning and acceleration of clinical trial recruitment based on machine learning have also significantly improved research efficiency, allowing new drugs to be used in patients faster. Therefore, for respiratory physicians, mastering and learning how to use artificial intelligence is an inevitable trend in the future.

The advancement of surgery results from the mutual improvement of surgeons' skills with the advancement of science and technology. In the 1990s, due to technological advancement, thoracoscopy was invented, and thoracic surgery entered the era of minimally invasive surgery. Thoracic surgeons can complete complicated operations such as radical resection of lung cancer, thymoma resection, and even tracheal carina reconstruction under video-assisted thoracic surgery (VATS). Subsequently, thoracic surgeons creatively proposed surgical approaches such as uniportal VATS and tubeless VATS to further improve enhanced recovery after surgery.

With the invention of the da Vinci robotic system in the 20th century, we entered the era of "semi-intelligent" surgery. The so-called da Vinci robotic system is actually just a remote-control system and cannot perform operations independently. It still requires the operation of human experts and does not perform real robotic surgery, so we prefer to call it "semiintelligent". However, with the advent of the robotic system, the increased human abilities have made surgical operations more stable and more refined, and surgeons have become calmer during the operation (because surgical gowns do not bind them). Later, the skills and wisdom of surgeons are always endless, and complicated and innovative operations such as uniportal da Vinci robotic surgery and tubeless da Vinci robotic carinal reconstruction surgery are performed endlessly.

As thoracic surgeons, we know clearly that surgery will never have the "best innovation", only the "next best innovation". Thoracic surgeons must understand the basics of artificial intelligence and learn to better understand its potential benefits instead of resisting innovation so that they can better evaluate, understand, and ultimately improve the safety of patients and themselves during the perioperative period. Surgical artificial intelligence has shown great potential in preoperative diagnosis, surgical planning, intraoperative guidance, surgical identification, surgical safety quality control, postoperative diagnosis, survival prediction, and other aspects. The final application in any aspect can change clinical practice, improve the efficiency of surgeons, improve patient safety, and improve patients' prognosis.

We organized this special series to allow respiratory physicians and thoracic surgeons to better understand the artificial intelligence technology currently applied to thoracic diseases, grasp the cutting-edge artificial intelligence cross-research progress, and inspire more respiratory physicians and thoracic surgeons to participate in the development and design of artificial intelligence-related research. The ultimate goal is to allow patients to receive better quality personalized treatment, which will lead to a better prognosis. 


\section{Acknowledgments}

Funding: None.

\section{Footnote}

Provenance and Peer Review: This article was commissioned by the editorial office, Fournal of Thoracic Disease, for the series "Artificial Intelligence in Thoracic Disease: from Bench to Bed". The article did not undergo external peer review.

Conflicts of Interest: Both authors have completed the ICMJE uniform disclosure form (available at https://dx.doi. org/10.21037/jtd-2021-42). The series "Artificial Intelligence in Thoracic Disease: from Bench to Bed" was commissioned by the editorial office without any funding or sponsorship. HL served as the unpaid Guest Editor of the series. JH served as the unpaid Guest Editor of the series and serves as an Executive Editor-in-Chief of the fournal of Thoracic Disease. The authors have no other conflicts of interest to declare.

Ethical Statement: The authors are accountable for all aspects of the work in ensuring that questions related to the accuracy or integrity of any part of the work are appropriately investigated and resolved.

Open Access Statement: This is an Open Access article distributed in accordance with the Creative Commons AttributionNonCommercial-NoDerivs 4.0 International License (CC BY-NC-ND 4.0), which permits the non-commercial replication and distribution of the article with the strict proviso that no changes or edits are made and the original work is properly cited (including links to both the formal publication through the relevant DOI and the license). See: https://creativecommons.org/licenses/by-nc$\mathrm{nd} / 4.0 \%$.

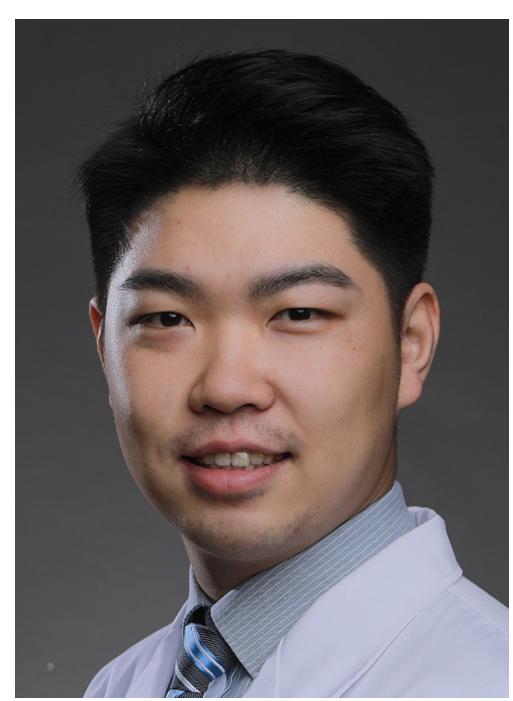

Hengrui Liang

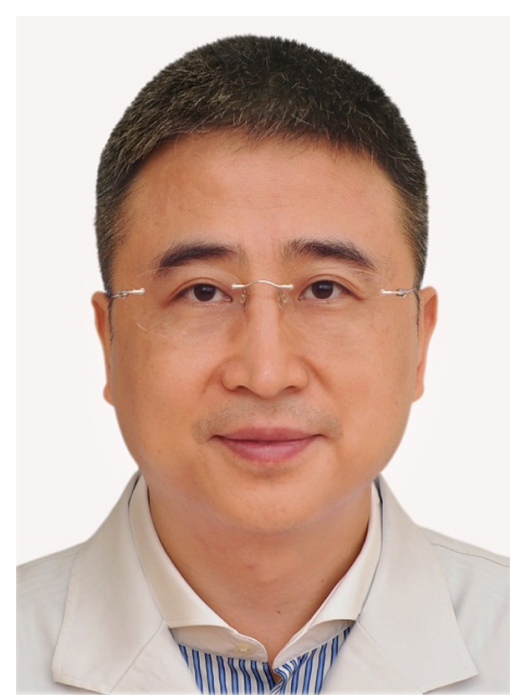

Jianxing $\mathrm{He}$ 


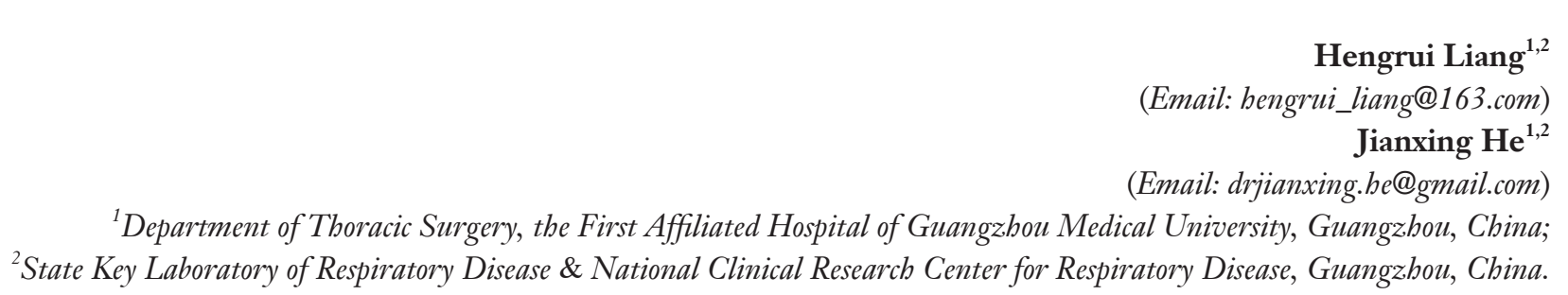

Submitted Nov 19, 2021. Accepted for publication Dec 09, 2021. doi: $10.21037 /$ jtd-2021-42

View this article at: https://dx.doi.org/10.21037/jtd-2021-42

Cite this article as: Liang $\mathrm{H}, \mathrm{He} \mathrm{J}$. Artificial intelligence in thoracic diseases: the next technology to improve individual precision medicine. J Thorac Dis 2021;13(12):6940-6942. doi: $10.21037 /$ jtd-2021-42 